\title{
Coping Strategies among Parents of Children with Acute Lymphoblastic Leukemia
}

\author{
Rosnah Sutan', Nahlah Abduljaleel Al-Saidi' ${ }^{1}$, Zarina Abdul Latiff², Hishamshah Mohd Ibrahim ${ }^{3}$ \\ ${ }^{1}$ Department of Community Health, Universiti Kebangsaan Malaysia, Kuala Lumpur, Malaysia \\ ${ }^{2}$ Department of Pediatrics, Universiti Kebangsaan Malaysia, Kuala Lumpur, Malaysia \\ ${ }^{3}$ Institute of Pediatrics, General Hospital Kuala Lumpur, Kuala Lumpur, Malaysia \\ Email: rosnah_sutan@yahoo.com
}

How to cite this paper: Sutan, R., Al-Saidi, N.A., Latiff, Z.A. and Ibrahim, H.M. (2017) Coping Strategies among Parents of Children with Acute Lymphoblastic Leukemia. Health, 9, 987-999.

https://doi.org/10.4236/health.2017.97071

Received: April 14, 2017

Accepted: July 3, 2017

Published: July 6, 2017

Copyright (c) 2017 by authors and Scientific Research Publishing Inc. This work is licensed under the Creative Commons Attribution International License (CC BY 4.0).

http://creativecommons.org/licenses/by/4.0/

(c) (i) Open Access

\begin{abstract}
Background: Having a child with acute lymphoblastic leukemia represents challenges to the family which may impact their quality of life. In such circumstances, parents use various coping strategies to face this stressful situation, and understanding the relation of coping strategies on quality of life among parents of children with acute lymphoblastic leukemia may provide professionals with ideas about how to support them which in turn may improve their quality of life. Aim: The aim of the present study was to assess the correlation between coping strategies and the health related quality of life of parents whose children are suffering from acute lymphoblastic leukemia. Study design: A cross-sectional design using guided self-administered questionnaire by a single researcher was used. Methods: A universal sample consisted of 299 parents of children with acute lymphoblastic leukemia (ALL) was recruited from Hospital Universiti Kebangsaan Malaysia and Kuala Lumpur Institute Pediatrics. The response rate was $98 \%$. The data collection tools were WHOQOL BREF which is the World Health Organization Quality of Life shorter version and Brief COPE questionnaires. Results: The results revealed that half of the parents perceived their health related quality of life as good. The highest scores for parents were reported on the social relationship domain meanwhile the lowest were reported on the environmental health domain. In regard to the coping strategies, it was found that religion was most frequently used while humor was the least to be used. Moreover, there was a significant positive relationship between quality of life of the parents and problem-focused coping style and a significant negative relationship with emotion-focused coping style. Conclusion: On the basis of the finding of present study, an appropriate intervention could be design to include program that promote the use of problem-focused copings such as active coping and planning and discourage the use of emotion-focused copings such as selfblaming to enhance parents' health related quality of life.
\end{abstract}




\section{Keywords}

Health Related QOL, Childhood Cancer, Leukemia, Coping

\section{Introduction}

Leukemia is the most common cancer among children, and it represent nearly one third of all pediatric cancers. In Malaysia, it is the most common cancer in children at the age group 0 - 14 years, representing $48 \%$ of cancers among boys and $44.5 \%$ among girls [1]. Due to the improvement of the treatment and management of childhood acute lymphoblastic leukemia (ALL), it was shifted from being life threatening disease to chronic disease. It also results in the shift of the child care from the hospital to home which necessitates change in the family roles and the preparedness to control their social activities, job commitments and all aspects of life. This radical change in the family life and the fear of losing the ill child has a great impact on the parents health related quality of life.

Research evidence suggests that parents of children with ALL showed symptoms of depression and anxiety [2] [3] [4], posttraumatic stress [5] [6], and stress [7] [8]. These symptoms may extend even after the cessation of the treatment [9] [10] [11]. Researchers suggest that instead of classify parents as depressed or stressed, it would be more helpful to investigate the holistic multidimensional concept of quality of life [12]. Quality of life is a broad concept that includes different aspects of life. According to the World Health Organization (WHO), it is defined as "an individual s perception of his/ her position in life in the context of the culture and value systems in which hel she lives, and in relation to his/ her goals, expectations, standards and concerns. It is a broad-ranging concept, incorporating in a complex way the person's physical health, psychological state, and level of independence, social relationships, and their relationship to salient features of their environment" [13].

Previous studies suggested that parents of children with chronic diseases like congenital heart disease [14], cerebral palsy [15], pervasive developmental disorders [16], and sickle cell anemia [17] reported poorer quality of life when compared with parents of healthy children. In the context of parents of children with cancers studies found impairment of health related quality of life among parents when compared with norms [18] [19] [20] [21].

Quality of life of the parents was suggested to be influenced by a variety of factors and how people cope with it is one of its determinants. Coping strategies have been postulated as one mechanism by which individuals respond to threats or stress. In the context of quality of life caregiver's of family of chronically ill patients, a critical review of 19 studies conducted from 1987 till 2004 found that stress coping methods is one of the possible predictors influencing caregivers' quality of life [22]. Stress is well known situation that affecting quality of life. People will try to cope by preventing problems from occurs but if the problem is already encountered, own self body response will automatically stimulated to 
overcome it. However, variation of how people cope will depends on their exposure and learnt experiences. There were many methods used to response to stress of having ill child has been reported by earlier studies. However, the commonest highlighted were the problem-focussed coping and emotion-focussed coping. People may not aware of what type they used but instrument to measure the coping methods has been heavily discussed in the literature and the commonest instrument used lately for researchers in Malaysia was the Brief COPE of Malay validated version [23].

Thus there is a need to investigate the relation of different coping strategies on quality of life among parents of children with ALL in present study. Findings of present study may help professionals with ideas about how to support parents whose children with ALL which in turn may improve parental quality of life and their children treatment management compliance. The aims of this study were to measure the health related quality of life (HRQOL) of parents of children with acute lymphoblastic leukemia and to assess its relationships with the coping style they use.

\section{Methods}

\subsection{Study Approach}

A cross-sectional study was conducted in Hospital Universiti Kebangsaan Malaysia and Kuala Lumpur Institute Pediatrics in the period from August 2012 to March 2013. To be eligible, parents should have a child aged between 0 - 18 years old diagnosed with ALL who were admitted to the ward or who had scheduled an appointment at the clinic or day care center, resides with the child since diagnosis, and should be able to understand Malay or English language. Parents of children at the end stage or with serious complications and child without parent as the guardian were excluded. Green 1991 [24] indicated that for testing the multiple correlation, a minimum of $\mathrm{N}>50+8 \mathrm{~m}$ (where $\mathrm{m}$ is the number independent variables) is required. In this study and at there are 21 independent variables. Therefore calculated sample size was 208 . Using convenience sampling, a total of 299 questionnaires were distributed to parents of children with ALL, among them only 293 questionnaires were returned (98\% response rate). One researcher was used to provide essential explanations to parents about the questionnaire before recruitment. Guided self-administered questionnaire was used to help parents who have doubt in answering some questions which not clear to them. Only one either father or mother of the child with ALL who gave the most care were selected.

\subsection{Study Instruments}

Data were collected using a structured questionnaire which consists of three sections. The first section covered the socio-demographic information, the second section consisted of the Malay version (or English) of World Health Organization Quality of Life Questionnaire WHOQOL-BREF questionnaire (WHOQOLBREF), the third section consisted of the Malay version (or English) Brief COPE 
scale.

\section{WHOQOL-BREF}

It is derived from the WHOQOL-100 which is developed collaboratively and field-tested across a number of cultural contexts. The validated Malay version [25] of the WHOQOL-BREF was used with permission to used has been granted. The 26-items WHOQOL-BREF consists of two overall items measuring general QOL and health condition and 24 items that are divided to four domains: physical health, psychological health, social relationships, and environment similar as Yusoff et al. (2010) [25]. Each item was rated on a 5-point Likert scale and the domain scores were transformed on a scale from 4 to 20 to enable comparisons to be made between domains composed of unequal numbers of items.

\section{Brief COPE}

Brief COPE consists of 28 items that measure 14 different coping strategies. The validated Malay version of the brief COPE [23] was used with permission granted. Participants rated their use of each coping strategy on a 4-point scale range from 1 ( $I$ haven't been doing this at all) to 4 ( $P$ ve been doing this a lot). The scales of the Brief COPE are divided into two coping styles by summing items into the following categories: problem-focused coping (Religion, Acceptance, Planning, Positive reframing, Active coping, Instrumental support, Emotional support, and Humor). The emotion-focused coping (Self-distraction, Denial, Venting, Behavioral disengagement, Self-blame and Substance abuse). The scores based on the sum of the scores of each subscales. These two coping styles were used in present operational study definition for easy interpreting into stress management plan for the parent. These two styles were following the concept written by Lazarus and Folkman [26]. Carver [27] suggested to use original scales rather than group into overall or sub categories. However, in dealing with parent of ALL's stress which affecting their qualities of life, the two styles were used for further exploration on steps taken when problems encountered according to their own socio cultural ways. Problem-focused coping was based on direct ways and the emotional-focused coping was indirect ways of problem solving which was related to stress management [28] [29].

\subsection{Study Analysis and Ethics}

Data were processed and analyzed by using Statistical package for Social Sciences version 21.0 (SPSS 21.0 for window). Descriptive statistics were used to describe the characteristics of the sample and their responses to the instruments. Pearson's correlation for normal distribution variables and Spearman's Rho test for non-normally distributed variables were performed to examine the strength and direction of the correlation between parents' HRQOL and coping strategies. Approval to conduct the present study was obtained from the research ethics committee of the Universiti Kebangsaan Malaysia and Pediatric Institute at GHKL through national Medical Research Ethic Committee of Ministry of health Malaysia. 


\section{Results}

There were 213 mothers (72.7\%) and 80 fathers $(27.3 \%)$ participated in the study, respondent's age ranged from 23 to 54 years old and the mean age was $37.7 \pm 6.67$ years. The majority were married 277 (94.5\%), Malay 220 (75.1\%), and with the highest education achieved was minimum of secondary education level $(78.8 \%)$, and about half of the respondents $(n=53,52.2 \%)$ were employed. In regard to the children's with ALL characteristics, 178 (60.8\%) of them were boys. The mean age for the children was $7.7 \pm 4.3$ years range from 5 months to 18 years. The mean age for the children at time of diagnosis was $4.5 \pm 2.9$ years. More than half of the children $(n=178,60.8 \%)$ were still under active treatment at the time of the study. Table 1 depicted the socio-demographic characteristics of the parents and their children.

\section{Quality of life}

With reference to the first question in the WHOQOL BREF scale (how would you rate your quality of life?), the results revealed that 149 (50.9\%) of the parents perceived their quality of life as good. Regarding the second question (how satisfied are you with your health?), 151 (51.1\%) of the parents reported that they were satisfied with their health (Table 2).

With regard to the domains of WHOQOL-BREF, the results of the present study revealed that the quality of life to be poorest in the environment domain (mean $14.08 \pm$ SD2.09) and best in social relationship domain (mean $15.03 \pm$ SD2.68). However, not much difference was found among the mean scores of the psychological and physical domains (Table 3 ).

\section{Coping strategies}

Table 4 indicates that parents of children with ALL used problem-focused coping style more than emotion-focused coping style. Among the problem-focused, religion practice was the mostly used strategy encountered. However among the emotion-focused coping style the most strategies used were self-distraction and venting while substance use was the least reported.

\section{Relation between parents' HRQOL and coping}

Problem-focused coping style was found to be positively, though weakly, related to overall and the 4 domains of the parents HRQOL. On the other hand, significant moderate negative correlation was found between emotion-focused coping strategies related to overall WHOQOL BREF scores and 3 domains. The physical health domain showed weak correlation (Table 5).

\section{Relation between child guardians' gender and parents' HRQOL}

Present study showed no significant difference between mothers and fathers as the child guardian in regard to HRQOL (Table 6). None of the HRQOL domain was found significant with parental gender.

\section{Discussion}

The diagnosis of acute lymphoblastic leukemia in a child constitutes a major challenge for the parents that may impact their quality of life. Previous studies reported that parents of children with cancer had poorer QOL compared with 
Table 1. Parents and children with ALL socio-demographic characteristics $(n=293)$.

\begin{tabular}{|c|c|c|}
\hline Characteristics & $\mathrm{n}=293$ & $\%$ \\
\hline \multicolumn{3}{|l|}{ PARENTS } \\
\hline \multicolumn{3}{|l|}{ Age group } \\
\hline$<30$ years & 35 & 11.9 \\
\hline $30-45$ years & 207 & 70.6 \\
\hline$\geq 45$ years & 51 & 17.4 \\
\hline Mean \pm SD & $37.7 \pm 6.67$ & \\
\hline \multicolumn{3}{|l|}{ Ethnicity } \\
\hline Malay & 220 & 75.1 \\
\hline Chinese & 45 & 15.4 \\
\hline Indians & 26 & 8.9 \\
\hline Others & 2 & 0.7 \\
\hline \multicolumn{3}{|l|}{ Gender } \\
\hline mother & 213 & 72.7 \\
\hline father & 80 & 27.3 \\
\hline \multicolumn{3}{|l|}{ Relation to the child } \\
\hline Biological parents & 289 & 98.4 \\
\hline Non-biological parents & 4 & 1.4 \\
\hline \multicolumn{3}{|l|}{ Marital status } \\
\hline Married & 277 & 94.5 \\
\hline Not married ${ }^{*}$ & 16 & 5.5 \\
\hline \multicolumn{3}{|l|}{ Employment } \\
\hline Employed & 153 & 52.2 \\
\hline Not employed & 140 & 47.8 \\
\hline \multicolumn{3}{|l|}{ Education } \\
\hline High school or less & 232 & 79.2 \\
\hline Diploma/degree/higher & 61 & 20.8 \\
\hline \multicolumn{3}{|l|}{ CHILDREN } \\
\hline \multicolumn{3}{|l|}{ Gender } \\
\hline Boy & 178 & 60.8 \\
\hline Girl & 115 & 39.2 \\
\hline \multicolumn{3}{|l|}{ Age } \\
\hline $0-6$ years & 101 & 34.5 \\
\hline $6-12$ years & 145 & 49.5 \\
\hline$>12$ years & 47 & 16.0 \\
\hline \multicolumn{3}{|l|}{ Age at diagnosis } \\
\hline$<6$ years & 206 & 70.3 \\
\hline $6-12$ years & 79 & 27 \\
\hline$>12$ years & 8 & 2.7 \\
\hline \multicolumn{3}{|l|}{ Duration of diagnosis } \\
\hline$<1$ year & 78 & 26.6 \\
\hline $1-3$ years & 102 & 34.8 \\
\hline$>3$ years & 113 & 38.6 \\
\hline \multicolumn{3}{|l|}{ Treatment status } \\
\hline Active treatment & 178 & 60.8 \\
\hline Follow up & 115 & 39.2 \\
\hline
\end{tabular}

${ }^{\star}$ Not married $=$ Single, divorced, separated or widowed. 
Table 2. Question 1 and 2 of the WHOQOL BREF $(n=293)$.

\begin{tabular}{cccc}
\hline & $\mathrm{n}=\mathbf{2 9 3}$ & $\%$ & Mean $\pm \mathrm{SD}$ \\
\hline Overall Perception of Parents of HRQOL & & & $\mathbf{3 . 5 7} \pm \mathbf{0 . 7 3}$ \\
Very poor & 5 & 1.7 & \\
Poor & 115 & 39.2 & \\
Neither good nor poor & 149 & 50.9 & \\
Good & 18 & 6.8 & \\
Very good & & & $\mathbf{3 . 6 9} \pm \mathbf{0 . 7 2}$ \\
Overall Perception of Parents Own Health & 2 & 0.7 & \\
Very dissatisfied & 7 & 2.4 & \\
Dissatisfied & 102 & 34.8 & \\
Seither satisfied nor dissatisfied & 151 & 51.1 & \\
Satisfied & 31 & 10.6 & \\
Very satisfied & &
\end{tabular}

Table 3. Mean scores of the domains of the WHOQOL-BREF.

\begin{tabular}{ccc}
\hline Domain & Range & Means \pm SD \\
\hline Physical capacity & $9-19$ & $14.54 \pm 2.20$ \\
Psychological wellbeing & $9-20$ & $14.60 \pm 2.07$ \\
Social relationship & $9-20$ & $15.03 \pm 2.68$ \\
Environment & $9-20$ & $14.08 \pm 2.09$ \\
Total QOL (sum of the 4 domains) & $8.75-19.75$ & $14.53 \pm 1.96$ \\
\hline
\end{tabular}

Table 4. Brief Cope Scale descriptive analysis.

\begin{tabular}{|c|c|c|}
\hline Coping strategies & Range & Means \pm SD \\
\hline Problem-focused coping strategies & $20-64$ & $46.99 \pm 7.4$ \\
\hline Religion & $2-8$ & $6.97 \pm 1.31$ \\
\hline Acceptance & $2-8$ & $6.60 \pm 1.35$ \\
\hline Planning & $2-8$ & $6.31 \pm 1.35$ \\
\hline Positive reframing & $2-8$ & $6.26 \pm 1.44$ \\
\hline Active coping & $2-8$ & $6.13 \pm 1.26$ \\
\hline Instrumental support & $2-8$ & $5.97 \pm 1.60$ \\
\hline Emotional support & $2-8$ & $5.57 \pm 1.55$ \\
\hline Humor & $2-8$ & $3.18 \pm 1.37$ \\
\hline Emotion-focused coping strategies & $12-26$ & $21.96 \pm 5.0$ \\
\hline Self-distraction & $2-8$ & $4.42 \pm 1.32$ \\
\hline Venting & $2-8$ & $4.23 \pm 1.44$ \\
\hline Denial & $2-8$ & $4.05 \pm 1.54$ \\
\hline Behavioral disengagement & $2-8$ & $3.70 \pm 1.42$ \\
\hline Self-blame & $2-8$ & $3.52 \pm 1.66$ \\
\hline Substance abuse & $2-6$ & $2.04 \pm 0.34$ \\
\hline
\end{tabular}


Table 5. Correlations between the parents' HRQOL and the coping strategies.

\begin{tabular}{cccccc}
\hline & Total WHOQOL & PC & PW & SR & EN \\
\hline Problem-focused coping & $0.19^{* *}$ & $0.12^{*}$ & $0.16^{* *}$ & $0.21^{* *}$ & $0.21^{* *}$ \\
Active coping & $0.23^{* *}$ & $0.23^{* *}$ & $0.19^{* *}$ & $0.21^{* *}$ & $0.23^{* *}$ \\
Instrumental support & 0.11 & 0.04 & 0.10 & 0.11 & 0.10 \\
Planning & $0.14^{*}$ & 0.08 & $0.16^{*}$ & $0.13^{*}$ & $0.17^{* *}$ \\
Acceptance & $0.25^{* *}$ & $0.19^{* *}$ & $20^{* *}$ & $0.24^{* *}$ & $0.22^{* *}$ \\
Emotional support & $0.13^{*}$ & 0.06 & 0.03 & $0.19^{* *}$ & $0.13^{*}$ \\
Humor & $-0.13^{*}$ & $-0.16^{* *}$ & -0.07 & $-0.14^{*}$ & -0.04 \\
Positive reframing & $0.22^{* *}$ & $0.19^{* *}$ & $0.18^{* *}$ & $0.19^{* *}$ & $0.21^{* *}$ \\
Religion & $0.21^{* *}$ & $0.16^{* *}$ & $0.23^{* *}$ & $0.21^{* *}$ & $0.17^{* *}$ \\
Emotion-focused coping & $-0.35^{* *}$ & $-0.26^{* *}$ & $-0.31^{* *}$ & $-0.30^{* *}$ & $-0.30^{* *}$ \\
Behavioral disengagement & $-0.25^{* *}$ & $-0.27^{* *}$ & $-0.23^{* *}$ & $-0.20^{* *}$ & $-0.16^{* *}$ \\
Denial & $-0.22^{* *}$ & $-0.19^{*}$ & $-0.15^{*}$ & $-0.25^{* *}$ & $-0.16^{* *}$ \\
Self-distraction & $-0.16^{* *}$ & $-0.12^{*}$ & -0.10 & $-0.15^{*}$ & -0.06 \\
Self-blame & $-0.44^{* *}$ & $-0.30^{* *}$ & $-0.39^{* *}$ & $-0.33^{* *}$ & $-0.39^{* *}$ \\
Substance abuse & 0.09 & -0.09 & -0.07 & -0.06 & -0.02 \\
Venting & $-0.17^{* *}$ & $-0.13^{*}$ & -0.10 & $-0.16^{*}$ & $-0.19^{* *}$ \\
\hline
\end{tabular}

${ }^{*} p<0.05,{ }^{*} p<0.01 \mathrm{PC}=$ Physical capacity, $\mathrm{PW}=$ psychological well-being, $\mathrm{SR}=$ Social relationships and $\mathrm{EN}=$ Environment well-being.

Table 6. Correlation of the parents' HRQOL by guardians' gender.

\begin{tabular}{cccccc}
\hline Variables & Total QOL & PC & PW & SR & EN \\
\hline Mothers & $14.48 \pm 1.94$ & $14.47 \pm 2.21$ & $14.59 \pm 2.06$ & $14.80 \pm 2.77$ & $14.05 \pm 2.09$ \\
Fathers & $14.69 \pm 2.01$ & $14.74 \pm 2.16$ & $14.63 \pm 2.09$ & $15.2 \pm 20.75$ & $14.18 \pm 2.09$ \\
$t($ df $)$ & $0.81(291)$ & $0.93(291)$ & $0.12(291)$ & $1.11(291)$ & $0.64(291)$ \\
$p$-value & 0.42 & 0.35 & 0.90 & 0.27 & 0.47 \\
\hline
\end{tabular}

$\mathrm{PC}=$ Physical capacity, $\mathrm{PW}=$ psychological well-being, $\mathrm{SR}=$ Social relationships and $\mathrm{EN}=$ Environment well-being.

population norms [18] [19], parents of healthy children [21], and parents of children with other chronic diseases [26].

In the present study most of the parents evaluated their overall QOL as "good" (50.9\%) or "neither good nor poor" (39.2\%). This can be explained by the fact that more than two-thirds of cases were disclosure the diagnosis over a year ago (at the time of the study), and according to the adaptation theory, the negative feelings and caregiving burden declines over time due to the development of new adaptation capacities [30]. The gender of the children' guardian was not significant in present study and it was consistent with other studies [19] [31] [32]. In Malaysia, the women were the main caregiver in providing care during child sickness. However, it was not seen any difference between father and mother in relation to child ALL. 
Among the quality of life assessment domains found in the present study, the social domain had the highest scores, while the environmental domain had the lowest scores. This result was against the study findings done in Sri Lanka which found about $47.1 \%$ of the parents of children with leukemia had low social quality QOL [20] and other study in Japan whose mothers reported low social QOL [21]. In Malaysia, other study related to Down syndrome, reported the highest scores was in the social relationship domain and the lowest scores in the environmental supports domain which was consistent with the current study findings [33].

The financial overburden may explain the low scores in the environmental health. In the current study, most of the parents have a low family income; parents reported income of RM 2500 or less. Furthermore, the majority of the parents attained highest education until secondary school level and $40 \%$ of them were unemployed which contributed to lower family income. The high scores of the social domain reflects that the parent's satisfaction with their personal relationships and social support which have positive effect in their well-being and adjustment to the situation.

In the present study, parents used both problem-focused and emotion- focused but tended to rely more on problem-focused coping strategies. Among the problem-focused coping styles, religion practice was mostly utilized. This can be explained by the respondents background of three fourths of them were Muslims Malay who believe that any stressful events is a test from God and thus tend to increase religious activities than usual. The use of religion as a coping strategy has been reported in previous studies on coping by caregivers and parents of cancer patients [34] [35] [36]. Part of the literature review of articles published since 1980 concern coping of parents of children with cancer found that praying and religion were among the mostly used coping strategies by parents [37]. The most frequently used emotion-focused coping strategies adopted by the parents in the present study were self-distraction.

The study findings revealed that problem-focused coping significantly positively, though weakly, related to overall HRQOL and with all of its domains, this result is consistent with other studies found that the more frequent use of problem-focused coping associated with lower levels of anxiety and depression in parents of children with cancer [38] [39]. In contrast to our findings, Greening and Stoppelbein [39] found that the frequent used of problem-solving strategies was associated with increased psychological symptoms among parents because adopting these strategies require confronting the stressor which may provoke anxiety.

On the other hand, significant moderate negative correlation was found between emotion-focused coping strategies and overall WHOQOL BREF scores and all its domains except for physical health domain where only small correlation were found. This finding indicating that the higher use of behavioral disengagement denial self-distraction self-blame substance abuse and venting strategies correlated to lower HRQOL levels. Previous studies reported that emotion- 
focused coping strategies associated with higher levels of psychological distress [8] [30]-[42].

The limitations noted in present study were:

- Conducted in two centers in Kuala Lumpur which may not reflect the general population of parents of children with ALL in Malaysia.

- The cross-sectional nature of the quantitative part whereby the data was collected only at one point of time

- The age of the children in our study ranged from newborn to 18 years old which may make it difficult to compare HRQOL among age groups.

- The sample consisted mostly of mothers

\section{Conclusion}

Present study used WHOQOL-BREF and it was found that the parents of children with ALL had higher scores for social relationship domain and lower scores for the environmental health domain. Several coping strategies were shown to demonstrate significant associations (weak to moderate) with parent's quality of life. However they tend to use problem-focused coping styles rather than the emotion-focused ones. Problem-focused coping helps parents in assessing and managing the situation and this will result in favorable aspects of quality of life, while self-distracting, self-blaming, denying or avoid the situation will delay the parents dealing with the problem resulting in negative side effects ending up by reducing their quality of life. On the basis of the present study findings, planning an appropriate intervention management, in future should promote the use of problem-focused copings such as active coping and planning and discourage the use of emotion-focused copings such as self-blaming to enhance parents' HRQOL.

\section{Acknowledgements}

All authors thank the Universiti Kebangsaan Malaysia who has approved and granted this study. Acknowledgment to the Pediatric wards staffs of UKMMC and Institute Pediatrics General Hospital Kuala Lumpur who gave support during respondent recruitment. Appreciation to all respondents involved in the present study and contributed to this research findings.

\section{References}

[1] Zainal Ariffin, O. and Nor Saleha, I. (2011) National Cancer Registry Report 2007. Ministry of Health, Malaysia.

[2] Erkan, S. and Kaplan, Y. (2009) A study on the Depression Levels of Mothers of Leukemic Children. Pakistan Journal of Social Sciences, 6, 42-47.

[3] Iqbal, A. and Siddiqui, K.S. (2002) Depression among Parents of Children with Acute Lymphoblastic Leukemia. Blue Collar, 6, 9.

[4] Kholasehzadeh, G., Shiryazdi, S., Neamatzadeh, H. and Ahmadi, N. (2014) Depression Levels among Mothers of Children with Leukemia. Iranian Journal of Pediatric Hematology Oncology, 4, 109-113.

[5] Barakat, L.P., Kazak, A.E., Meadows, A.T., Casey, R., Meeske, K. and Stuber, M.L. 
(1997) Families Surviving Childhood Cancer: A Comparison of Posttraumatic Stress Symptoms with Families of Healthy Children. Journal of Pediatric Psychology, 22, 843-859. https://doi.org/10.1093/jpepsy/22.6.843

[6] Kazak, A.E., Alderfer, M., Rourke, M.T., Simms, S., Streisand, R. and Grossman, J.R. (2004) Posttraumatic Stress Disorder (PTSD) and Posttraumatic Stress Symptoms (PTSS) in Families of Adolescent Childhood Cancer Survivors. Journal of Pediatric Psychology, 29, 211-219. https://doi.org/10.1093/jpepsy/jsh022

[7] Masa'Deh, R., Collier, J. and Hall, C. (2012) Parental Stress When Caring for a Child with Cancer in Jordan: A Cross-Sectional Survey. Health and Quality of Life Outcomes, 10, 88. https://doi.org/10.1186/1477-7525-10-88

[8] Zarina, A., Radhiyah, R., Hamidah, A., Zakaria, S.Z.S. and Jamal, R. (2012) Parenting stress in Childhood Leukaemia. Medicine \& Health, 7, 73-83.

[9] Best, M., Streisand, R., Catania, L. and Kazak, A.E. (2001) Parental Distress during Pediatric Leukemia and Posttraumatic Stress Symptoms (PTSS) after Treatment Ends. Journal of Pediatric Psychology, 26, 299-307. https://doi.org/10.1093/jpepsy/26.5.299

[10] Kazak, A.E. and Barakat, L.P. (1997) Brief Report: Parenting Stress and Quality of Life during Treatment for Childhood Leukemia Predicts Child and Parent Adjustment after Treatment Ends. Journal of Pediatric Psychology, 22, 749-758.

https://doi.org/10.1093/jpepsy/22.5.749

[11] Norberg, Lindblad and Boman (2005) Parental Traumatic Stress during and after Paediatric Cancer Treatment. Acta Oncologica, 44, 382-388.

https://doi.org/10.1080/02841860510029789

[12] Vrijmoet-Wiersma, C.M., van Klink, J.M., Kolk, A.M., Koopman, H.M., Ball, L.M. and Maarten Egeler, R. (2008) Assessment of Parental Psychological Stress in Pediatric Cancer: A Review. Journal of Pediatric Psychology, 33, 694-706. https://doi.org/10.1093/jpepsy/jsn007

[13] WHO (1999) Annotated Bibliography of the WHO Quality of Life Assessment Instrument-WHOQOL. WHO/MNH/MHP/98.4.Rev.2. http://www.who.int/healthinfo/survey/whoqol-qualityoflife/en/

[14] Lawoko, S. and Soares, J.J. (2003) Quality of Life among Parents of Children with Congenital Heart Disease, Parents of Children with Other Diseases and Parents of Healthy Children. Quality of Life Research, 12, 655-666. https://doi.org/10.1023/A:1025114331419

[15] Okurowska-Zawada, B., Kułak, W. and Sienkiewicz, D. (2011) Quality of Life of Parents of Children with Cerebral Palsy. Progress in Health Sciences, 1, 116-123.

[16] Yamada, A., Kato, M., Suzuki, M., Suzuki, M., Watanabe, N., Akechi, T. and Furukawa, T.A. (2012) Quality of Life of Parents Raising Children with Pervasive Developmental Disorders. BMC Psychiatry, 12, 119. https://doi.org/10.1186/1471-244X-12-119

[17] Van den Tweel, X.W., Hatzmann, J., Ensink, E., van der Lee, J.H., Peters, M., Fijnvandraat, K. and Grootenhuis, M. (2008) Quality of Life of Female Caregivers of Children with Sickle Cell Disease: A Survey. Haematologica, 93, 588-593. https://doi.org/10.3324/haematol.11610

[18] Eiser, C., Eiser, J.R. and Stride, C.B. (2005) Quality of Life in Children Newly Diagnosed with Cancer and Their Mothers. Health and Quality of Life Outcomes, 3, 29. https://doi.org/10.1186/1477-7525-3-29

[19] Klassen, A.F., Klaassen, R., Dix, D., Pritchard, S., Yanofsky, R., O’Donnell, M., Sung, L., et al. (2008) Impact of Caring for a Child with Cancer on Parents' Health- 
Related Quality of Life. Journal of Clinical Oncology, 26, 5884-5889. https://doi.org/10.1200/JCO.2007.15.2835

[20] Pathirana, T.I., Goonawardena, C. and Wijesiriwardane, I. (2014) Quality of Life of Caregivers and Impact on the Nuclear Family of Children with Leukaemia in the National Cancer Institute of Sri Lanka. Journal of the Postgraduate Institute of Medicine, 2, E18. https://doi.org/10.4038/jpgim.7863

[21] Yamazaki, S., Sokejima, S., Mizoue, T., Eboshida, A. and Fukuhara, S. (2005) Health-Related Quality of Life of Mothers of Children with Leukemia in Japan. Quality of Life Research, 14, 1079-1085. https://doi.org/10.1007/s11136-004-3288-Z

[22] Lim, J.W. and Zebrack, B. (2004) Caring for Family Members with Chronic Physical Illness: A Critical Review of Caregiver Literature. Health and Quality of Life Outcomes, 2, 50. https://doi.org/10.1186/1477-7525-2-50

[23] Yusoff, N., Low, W. and Yip, C. (2010) Reliability and Validity of the Malay Version of Brief COPE Scale: A Study on Malaysian Women Treated with Adjuvant Chemotherapy for Breast Cancer. Malaysian Journal of Psychiatry, 18.

[24] Green, S.B. (1991) How Many Subjects Does It Take to Do a Regression Analysis. Multivariate Behavioral Research Journal, 26, 499-510.

https://doi.org/10.1207/s15327906mbr2603_7

[25] Hasanah, C.I., Naing, L. and Rahman, A.R. (2003) World Health Organization Quality of Life Assessment: Brief Version in Bahasa Malaysia. Medical Journal of Malaysia, 58, 79-88.

[26] Carver, C.S. (1997) You Want to Measure Coping but Your Protocol's Too Long: Consider the Brief COPE. International Journal of Behavioral Medicine, 4, 92-100. https://doi.org/10.1207/s15327558ijbm0401_6

[27] Lazarus, R.S. and Folkman, S. (1984) Stress, Appraisal, and Coping. Springer, New York.

[28] Judge, S.L. (1998) Parental Coping Strategies and Strengths in Families of Young Children with Disabilities. Family Relations, 47, 263-268. https://doi.org/10.2307/584976

[29] Cordella, M. and Poian, S. (2014) Behavioural Oncology: Psychological, Communicative, and Social Dimensions, Springer, Berlin.

https://doi.org/10.1007/978-1-4614-9605-2

[30] Townsend, A., Noelker, L., Deimling, G. and Bass, D. (1989) Longitudinal Impact of Inter-Household Care-Giving on Adult Children's Mental Health. Psychology and Aging, 4, 393. https://doi.org/10.1037/0882-7974.4.4.393

[31] Goldbeck, L. (2006) The Impact of Newly Diagnosed Chronic Paediatric Conditions on Parental Quality of Life. Quality of Life Research, 15, 1121-1131. https://doi.org/10.1007/s11136-006-0068-y

[32] Kalyva, E. and Melonashi, E. (2015) Parental Perceptions of Health-Related Quality of Life of Albanian Children with Epilepsy. Health Psychology Research, 3, 2244. https://doi.org/10.4081/hpr.2015.2244

[33] Geok, C.K., Abdullah, K.L. and Kee, L.H. (2013) Quality of Life among Malaysian Mothers with a Child with Down Syndrome. International Journal of Nursing Practice, 19, 381-389. https://doi.org/10.1111/ijn.12083

[34] Hashemi, F., Sh, R., Sharif, F. and Shahriari, M. (2007) Coping Strategies Used by Parents of Children with Cancer in Shiraz, Southern Iran. Iranian Red Crescent Medical Journal, 2007, 124-128.

[35] Kohlsdorf, M. and Costa Junior, Á.L. (2011) Coping Strategies and Caregiver's Anxiety in Pediatric Oncohematology. Psicologia: Reflexão e Crítica, 24, 272-280. 
[36] Nair, D. (2014) Coping Strategies Used by Mothers' of Children with Leukemia in Pune, India. Acta Medica Scientia, 1, 6-8.

[37] Grootenhuis, M.A. and Last, B.F. (1997) Adjustment and Coping by Parents of Children with Cancer: A Review of the Literature. Support Care Cancer, 5, 466-484. https://doi.org/10.1007/s005200050116

[38] Compas, B.E., Bemis, H., Gerhardt, C.A., Dunn, M.J., Rodriguez, E.M., Desjardins, L., Vannatta, K., et al. (2015) Mothers and Fathers Coping with Their Children's Cancer: Individual and Interpersonal Processes. Health Psychology: Official Journal of the Division of Health Psychology, American Psychological Association, 34, 783793. https://doi.org/10.1037/hea0000202

[39] Greening, L. and Stoppelbein, L. (2007) Brief Report: Pediatric Cancer, Parental Coping Style, and Risk for Depressive, Posttraumatic Stress, and Anxiety Symptoms. Journal of Pediatric Psychology, 32, 1272-1277. https://doi.org/10.1093/jpepsy/jsm057

[40] Norberg, Lindblad and Boman (2005) Coping Strategies in Parents of Children with Cancer. Social Science \& Medicine, 60, 965-975.

[41] Grootenhuis, M.A. and Last, B.F. (1997) Predictors of Parental Emotional Adjustment to Childhood Cancer. Psycho-Oncology, 6, 115-128.

https://doi.org/10.1002/(SICI)1099-1611(199706)6:2<115::AID-PON252>3.0.CO;2$\underline{\mathrm{D}}$

[42] Trask, P.C., Paterson, A.G., Trask, C.L., Bares, C.B., Birt, J. and Maan, C. (2003) Parent and Adolescent Adjustment to Pediatric Cancer: Associations with Coping, Social Support, and Family Function. Journal of Pediatric Oncology Nursing, 20, 36-47. https://doi.org/10.1053/jpon.2003.5

Submit or recommend next manuscript to SCIRP and we will provide best service for you:

Accepting pre-submission inquiries through Email, Facebook, LinkedIn, Twitter, etc. A wide selection of journals (inclusive of 9 subjects, more than 200 journals)

Providing 24-hour high-quality service

User-friendly online submission system

Fair and swift peer-review system

Efficient typesetting and proofreading procedure

Display of the result of downloads and visits, as well as the number of cited articles

Maximum dissemination of your research work

Submit your manuscript at: http://papersubmission.scirp.org/

Or contact health@scirp.org 